\title{
From a Dissymmetrical Oxamidate Ligand to a 2D Coordination Polymer: Synthesis, Crystal Structure and Magnetic Properties
}

\author{
Bao Lin Liu ${ }^{\mathrm{a}}$, Juan Dang ${ }^{\mathrm{a}}$, Shuang Quan Zang ${ }^{\mathrm{b}}$, Qing Lun Wang ${ }^{\mathrm{c}}$, and Ruo Jie Tao ${ }^{\mathrm{a}}$ \\ ${ }^{a}$ Institute of Molecular and Crystal Engineering, College of Chemistry and Chemical Engineering, \\ Henan University, Kaifeng 475001, P. R. China \\ ${ }^{b}$ Department of Chemistry, Zhengzhou University, Henan 450052, P. R. China \\ ${ }^{c}$ Department of Chemistry, Nankai University, Tianjin 300071, P. R. China \\ Reprint requests to Prof. Ruo Jie Tao. Fax: +86-378-3881960. E-mail: rjtao@henu.edu.cn
}

Z. Naturforsch. 2010, 65b, 1240 - 1244; received May 23, 2010

\begin{abstract}
A new dissymmetrical oxamidate ligand has been used to construct a metal-organic network. Using this ligand, a novel coordination polymer, namely $\left\{[\mathrm{Cu}(\text { obea })]_{2} \mathrm{Cu} \cdot \mathrm{CH}_{3} \mathrm{OH} \cdot \mathrm{H}_{2} \mathrm{O}\right\}_{n}(\mathbf{1})\left[\mathrm{H}_{3}\right.$ obea $=$ $N 1$-(2-carboxyphenyl)-N2-(2-hydroxyethyl)oxalamide] has been synthesized and characterized by single-crystal X-ray analysis. The structure of complex 1 consists of neutral trinuclear complex units. Through syn-anti carboxylate bridges, the complex features a $2 \mathrm{D}$ structure with a helical substructure. Its magnetic properties have been investigated.
\end{abstract}

Key words: Oxamidate Ligand, Crystal Structure, Magnetic Properties

\section{Introduction}

The crystal engineering of solid-state metal coordination supramolecules is one of the most active research topics of current chemistry and molecular science due to the theoretical aspects related to the topologies of novel networks with inner cavities and channels [1], as well as their potential applications in catalysis [2], host-guest chemistry [3], and molecular electronics [4]. Self-assembly of suitably designed ligands with transition metal ions allows the creation of inorganic architectures with defined geometry and special properties [5-7].

It is well known that a carboxylate group can bridge two metal ions to give rise to a wide variety of polynuclear complexes ranging from discrete entities to threedimensional systems [8-10]. In these complexes, a carboxylate group can assume many types of bridging conformations, the most important being triatomic syn-syn, anti-anti, syn-anti, and monoatomic [11]. As expected, the magnetic properties are closely related to the bridging conformation adopted by the carboxylate group in these polynuclear systems. It should be noted that, as far as we know, only a few fully structurally and magnetically characterized singly syn-anti carboxylate-bridged complexes have been reported so far [12-15].

Oxamidate derivatives are known to be versatile organic ligands. One of the most outstanding characters

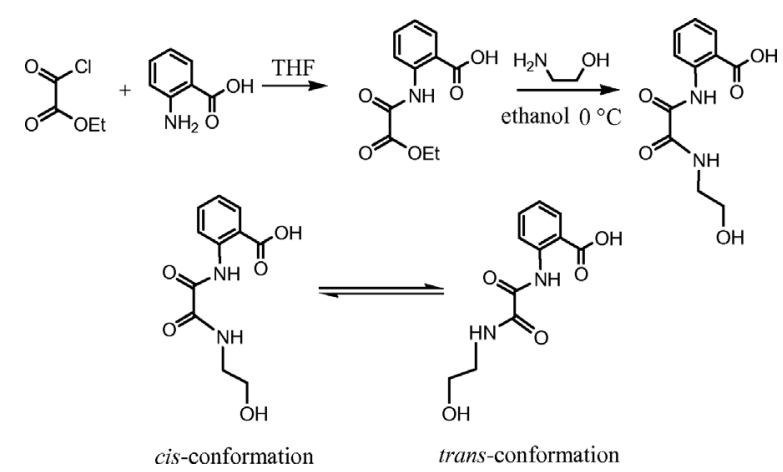

Scheme 1. Synthetic route to ligand $\mathrm{H}_{3}$ obea.

of these ligands is the easy transformation of cis-trans conformations, which makes it practical to design tunable molecular materials with extended structures and desired properties. The flexibility can give rise to a rich variety of complexes and extended structures, but it allows much less control over the final type of complex obtained [16].

With these facts in mind, the new dissymmetrical ligand N1-(2-carboxyphenyl)-N2-(2-hydroxyethyl)oxalamide, abbreviated as $\mathrm{H}_{3}$ obea, has been prepared in this work (Scheme 1). Based on this ligand, we describe the synthesis, crystal structure and magnetic properties of a novel coordination polymer, namely $\left\{[\mathrm{Cu}(\text { obea })]_{2} \mathrm{Cu} \cdot \mathrm{CH}_{3} \mathrm{OH} \cdot \mathrm{H}_{2} \mathrm{O}\right\}_{n}$ (1), which is a $2 \mathrm{D}$ framework containing both dissymmetri- 
cal trans-oxamidate bridges and syn-anti carboxylate bridges.

\section{Experimental Section}

Materials

$\mathrm{Cu}\left(\mathrm{ClO}_{4}\right)_{2} \cdot 6 \mathrm{H}_{2} \mathrm{O}$ was prepared as an in-house reagent. Other chemicals were commercial reagent grade and used without further purification.

Caution! Perchlorates are potentially explosive, thus only a small amount of material should be prepared and handled with care.

\section{Synthesis of the ligand $\mathrm{H}_{3}$ obea}

A $50 \mathrm{mmol}(6.83 \mathrm{~g})$ portion of ethyl oxalyl chloride in $10 \mathrm{~mL}$ of THF (THF = tetrahydrofuran) was added dropwise into $40 \mathrm{~mL}$ of a THF solution of $50 \mathrm{mmol}(6.86 \mathrm{~g})$ of anthranilic acid. After $1 \mathrm{~h}$, the mixture was added dropwise to a solution which contained $20 \mathrm{~mL}$ of absolute ethanol and $30 \mathrm{~mL}$ of ethanolamine at $0{ }^{\circ} \mathrm{C}$. The resulting solution was stirred for $24 \mathrm{~h}$, and $\mathrm{H}_{3}$ obea was precipitated as a colorless powder, washed with diethyl ether and dried under vacuum. Yield: $10.8 \mathrm{~g}(86 \%)$. - Anal. for $\mathrm{C}_{11} \mathrm{H}_{12} \mathrm{~N}_{2} \mathrm{O}_{5}$ : calcd. C 52.38, H 4.79, N 11.11; found C 52.36, H 4.80, $\mathrm{N} 11.14 \%$. - IR $(\mathrm{KBr}): v_{\mathrm{C}=\mathrm{O}}($ oxamidate group) $=1636$; $v_{\mathrm{as}(\mathrm{COO})}\left(v_{\mathrm{COOH}}\right.$ un-ionized $)=1672 \mathrm{~cm}^{-1}$.

Synthesis of the complex $\left\{[\mathrm{Cu}(\text { obea })]_{2} \mathrm{Cu} \cdot \mathrm{CH}_{3} \mathrm{OH} \cdot \mathrm{H}_{2} \mathrm{O}\right\}_{n}$ (1)

$\mathrm{H}_{3}$ obea (0.1 mmol, $\left.0.0252 \mathrm{~g}\right), \mathrm{NaOH}(0.3 \mathrm{mmol}, 0.012 \mathrm{~g})$ and $\mathrm{CuCl}_{2} \cdot 2 \mathrm{H}_{2} \mathrm{O}(0.1 \mathrm{mmol}, 0.017 \mathrm{~g})$ were dissolved in water $(5 \mathrm{~mL})$ in a test tube. A solution of $\mathrm{Cu}\left(\mathrm{ClO}_{4}\right)_{2} \cdot 6 \mathrm{H}_{2} \mathrm{O}$ $(0.1 \mathrm{mmol}, 0.0371 \mathrm{~g})$ in methanol $(5 \mathrm{~mL})$ was then carefully added to the top of this solution without disturbing it. Blue block-shaped single crystals suitable for X-ray analysis were obtained after four weeks. Yield: $46 \%$. - Anal. for $\mathrm{C}_{23} \mathrm{H}_{21} \mathrm{~N}_{4} \mathrm{O}_{12} \mathrm{Cu}_{3}$ : calcd. C 37.53, $\mathrm{H}$ 2.88, $\mathrm{N}$ 7.61; found: C $37.43, \mathrm{H} 2.83, \mathrm{~N} 7.67 \%$. - IR (KBr): $v_{\mathrm{C}=\mathrm{O}}=1628 \mathrm{~cm}^{-1}$.

\section{Physical measurements}

Elemental analyses for carbon, hydrogen and nitrogen were performed on a Perkin-Elmer 2400II elemental analyzer. The infrared spectra were recorded on an Avatar360 spectrometer using $\mathrm{KBr}$ pellets in the range of 400 $4000 \mathrm{~cm}^{-1}$. Variable temperature magnetic susceptibility data were obtained on microcrystalline samples from 5 to $300 \mathrm{~K}$ in a magnetic field of $10 \mathrm{KG}$, using a Quantum Design MPMS-7 SQUID magnetometer. Diamagnetic corrections were made with Pascal parameters for all constituent atoms.
Table 1. Crystallographic data and refinement parameters for complex 1.

\begin{tabular}{ll}
\hline Empirical formula & $\mathrm{C}_{23} \mathrm{H}_{22} \mathrm{~N}_{4} \mathrm{O}_{12} \mathrm{Cu}_{3}$ \\
Formula weight & 737.07 \\
Crystal system & monoclinic \\
Space group & $P 2_{2} / c$ \\
$a, \AA$ & $10.5442(10)$ \\
$b, \AA$ & $7.1479(7)$ \\
$c, \AA$ & $17.5062(17)$ \\
$\beta$, deg & $105.465(2)$ \\
$V, \AA^{3}$ & $1271.7(2)$ \\
$Z$ & 2 \\
$D_{\text {calc }}, \mathrm{g} \mathrm{cm}^{-3}$ & 1.93 \\
$\mu\left(\right.$ Mo $\left.K_{\alpha}\right), \mathrm{mm}^{-1}$ & 2.6 \\
$T, \mathrm{~K}$ & $293(2)$ \\
$\lambda, \AA$ & 0.71073 \\
Index ranges & $-11 \leq h \leq 12,-8 \leq k \leq 7$, \\
& $-20 \leq l \leq 20$ \\
Refl. total $/$ independ. / $R_{\text {int }}$ & $6119 / 2238 / 0.0581$ \\
Ref. parameters & 228 \\
$R 1 / w R 2^{\mathrm{a}}[I \geq 2 \sigma(I)]$ & $0.0492 / 0.1248$ \\
$R 1 / w R 2^{\mathrm{a}}($ all data $)$ & $0.0690 / 0.1317$ \\
Goodness-of-fit & 1.064 \\
$\Delta \rho_{\text {fin }}($ max $/$ min $), \mathrm{e} \AA^{-3}$ & $0.875 /-0.495$ \\
\hline
\end{tabular}

a $R 1=\Sigma|| F_{\mathrm{o}}|-| F_{\mathrm{c}} \| / \Sigma\left|F_{\mathrm{o}}\right|, w R 2=\left[\Sigma w\left(F_{\mathrm{o}}^{2}-{F_{\mathrm{c}}}^{2}\right)^{2} / \Sigma w\left(F_{\mathrm{o}}{ }^{2}\right)^{2}\right]^{1 / 2}$, $w=\left[\begin{array}{lll}\sigma^{2}\left(F_{\mathrm{o}}{ }^{2}\right)+\left(\begin{array}{lll}0.0720 & P\end{array}\right)^{2}+0.1919 & P\end{array}\right]^{-1}$, where $P=$ $\left(\operatorname{Max}\left(F_{\mathrm{o}}{ }^{2}, 0\right)+2 F_{\mathrm{c}}{ }^{2}\right) / 3 ; \quad \mathrm{b} \quad \mathrm{GoF}=\left[\sum w\left(F_{\mathrm{o}}{ }^{2}-F_{\mathrm{c}}{ }^{2}\right)^{2} /\left(n_{\mathrm{obs}}-\right.\right.$ $\left.n_{\text {param }}\right]^{1 / 2}$.

Table 2. Selected bond lengths (Å) and angles (deg) for complex 1.

\begin{tabular}{|c|c|c|c|}
\hline$\overline{\mathrm{Cu}(1)-\mathrm{N}(2)^{\# 1}}$ & $1.932(4)$ & $\mathrm{Cu}(1)-\mathrm{N}(2)$ & $1.932(4)$ \\
\hline $\mathrm{Cu}(1)-\mathrm{O}(3)^{\# 1}$ & $1.964(3)$ & $\mathrm{Cu}(1)-\mathrm{O}(3)$ & $1.964(3)$ \\
\hline $\mathrm{Cu}(2)-\mathrm{O}(1)$ & $1.894(4)$ & $\mathrm{Cu}(2)-\mathrm{O}(4)$ & $1.934(3)$ \\
\hline $\mathrm{Cu}(2)-\mathrm{N}(1)$ & $1.959(4)$ & $\mathrm{Cu}(2)-\mathrm{O}(2)^{\# 2}$ & $1.958(3)$ \\
\hline $\mathrm{Cu}(2)-\mathrm{O}(1 \mathrm{~W})$ & $2.533(9)$ & $\mathrm{Cu}(2)-\mathrm{O}(6)$ & $2.549(10)$ \\
\hline $\mathrm{N}(2)-\mathrm{Cu}(1)-\mathrm{N}(2)^{\# 1}$ & 180 & $\mathrm{~N}(2)^{\# 1}-\mathrm{Cu}(1)-\mathrm{O}(3)^{\# 1}$ & $83.90(15)$ \\
\hline $\mathrm{N}(2)-\mathrm{Cu}(1)-\mathrm{O}(3)^{\# 1}$ & $96.10(15)$ & $\mathrm{N}(2)^{\# 1}-\mathrm{Cu}(1)-\mathrm{O}(3)$ & $96.10(15)$ \\
\hline $\mathrm{N}(2)-\mathrm{Cu}(1)-\mathrm{O}(3)$ & $83.90(15)$ & $\mathrm{O}(3)^{\# 1}-\mathrm{Cu}(1)-\mathrm{O}(3)$ & 180 \\
\hline $\mathrm{O}(1)-\mathrm{Cu}(2)-\mathrm{O}(2)^{\# 2}$ & $86.20(15)$ & $\mathrm{O}(4)-\mathrm{Cu}(2)-\mathrm{O}(2)^{\# 2}$ & 93.94(15) \\
\hline $\mathrm{O}(1)-\mathrm{Cu}(2)-\mathrm{O}(4)$ & $172.93(18)$ & $\mathrm{O}(1)-\mathrm{Cu}(2)-\mathrm{N}(1)$ & $93.43(15)$ \\
\hline $\mathrm{O}(4)-\mathrm{Cu}(2)-\mathrm{N}(1)$ & $86.55(15)$ & $\mathrm{O}(2)^{\# 2}-\mathrm{Cu}(2)-\mathrm{N}(1)$ & $178.98(15)$ \\
\hline $\mathrm{O}(1)-\mathrm{Cu}(2)-\mathrm{O}(1 \mathrm{~W})$ & $88.0(3)$ & $\mathrm{O}(4)-\mathrm{Cu}(2)-\mathrm{O}(1 \mathrm{~W})$ & $98.9(3)$ \\
\hline $\mathrm{O}(2)^{\# 2}-\mathrm{Cu}(2)-\mathrm{O}(1 \mathrm{~W})$ & $100.2(2)$ & $\mathrm{N}(1)-\mathrm{Cu}(2)-\mathrm{O}(1 \mathrm{~W})$ & $78.9(2)$ \\
\hline $\mathrm{O}(1)-\mathrm{Cu}(2)-\mathrm{O}(6)$ & $85.5(3)$ & $\mathrm{O}(4)-\mathrm{Cu}(2)-\mathrm{O}(6)$ & $87.6(3)$ \\
\hline $\mathrm{O}(2)^{\# 2}-\mathrm{Cu}(2)-\mathrm{O}(6)$ & $78.6(2)$ & $\mathrm{N}(1)-\mathrm{Cu}(2)-\mathrm{O}(6)$ & $102.4(2)$ \\
\hline $\mathrm{O}(1 \mathrm{~W})-\mathrm{Cu}(2)-\mathrm{O}(6)$ & 173.5(3) & & \\
\hline
\end{tabular}

\section{$X$-Ray analysis}

A single crystal with dimensions $0.14 \times 0.13 \times$ $0.06 \mathrm{~mm}^{3}$ was used for the structure determination using a Bruker SMART APEX CCD diffractometer with graphitemonochromatized $\operatorname{Mo} K_{\alpha}$ radiation $(\lambda=0.71073 \AA)$ at r. t. ( $\omega$ scan technique). Lorentz, polarization and absorption corrections were applied. The crystal structure was solved by Direct Methods with the SHELXTL program and refined 
by full-matrix least-squares procedures with anisotropic displacement parameters for all non-hydrogen atoms [17]. All $\mathrm{H}$ atoms could be detected in the difference electron density maps. Nevertheless, they were positioned at idealized positions and refined using a riding model. Analytical expressions of neutral-atom scattering factors were employed, and anomalous dispersion corrections were incorporated. Crystallographic data are summarized in Table 1. Selected bond lengths and bond angles are shown in Table 2.

CCDC-706284 contains the supplementary crystallographic data for this paper. These data can be obtained free of charge from The Cambridge Crystallographic Data Centre via www.ccdc.cam.ac.uk/data_request/cif.

\section{Results and Discussion}

IR spectra

The ligand $\mathrm{H}_{3}$ obea exhibits one $v_{\mathrm{C}=\mathrm{O}}$ vibration band of the oxamidate group at $c a .1636 \mathrm{~cm}^{-1}$ [18], one $v_{\mathrm{as}(\mathrm{COO})}$ vibration band at ca. $1672 \mathrm{~cm}^{-1}\left(v_{\mathrm{COOH}}\right.$ un-ionized) [19], and $v_{\mathrm{N}-\mathrm{H}}$ bands of the oxamidate group at ca. 3082 and $3102 \mathrm{~cm}^{-1}$. These bands are all missing in the spectrum of the complex because of the loss of the protons of both the $\mathrm{COOH}$ and N-H (oxamidate group) groups. It must be noted that one new sharp strong band observed in the complex $1\left(1628 \mathrm{~cm}^{-1}\right)$ is the result of an overlap between $v_{\mathrm{as}(\mathrm{COO})}$ of the ionized carboxylate group and the vibration of the oxamidate group $\left(v_{\mathrm{C}=\mathrm{O}}\right)$ acting in a bidendate mode. No peak can be assigned unambiguously to metal-ligand vibrations in the range below $600 \mathrm{~cm}^{-1}$, since the ligand itself has several absorptions in this region.

\section{Description of the crystal structure}

$\mathrm{X}$-Ray single crystal structure analysis has revealed that complex 1 crystallizes in the space group $P 22_{1} / c$. As shown in Fig. 1, complex 1 consists of a trinuclear neutral molecule, one water molecule, and one methanol molecule. The trinuclear neutral molecule has a centrosymmetric structure with a $\mathrm{Cu} 1$ ion in its center. Two oxamidate anions act as bridges between the central and the outer metal ions. The $\mathrm{Cu}-\mathrm{Cu}$ distance through the oxamido bridge is 5.189(5) $\AA$. The coordination geometry around the $\mathrm{Cu} 1$ ion is approximately square-planar, composed of two oxygen atoms and two nitrogen atoms from two trans-oxamidate bridges. The $\mathrm{Cu} 2$ ion has a distorted octahedral coordination, the equational positions being composed of two oxygen atoms $(\mathrm{O} 1, \mathrm{O} 4)$, and one nitrogen atom (N1) of the trans-oxamidate bridge, and one carboxylic oxy-

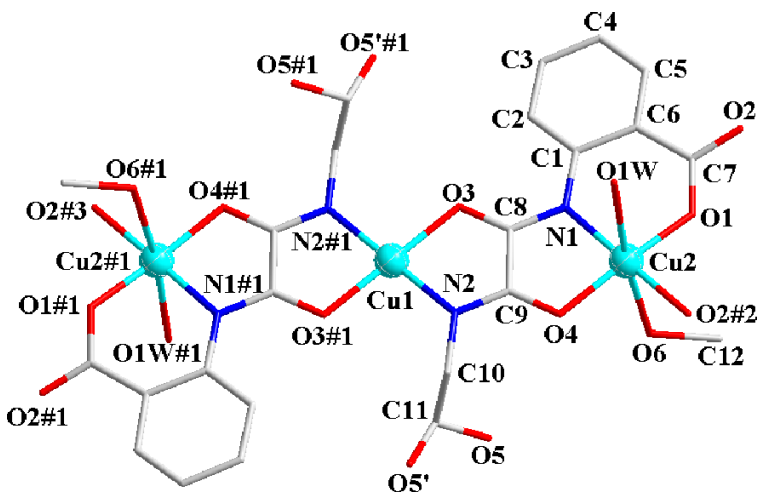

Fig. 1. Trinuclear unit of complex 1 (symmetry codes: $\# 1-x+3,-y+3,-z ; \# 2-x+2,-y+1 / 2,-z-1 / 2$; $\# 3-x+2, y-1 / 2,-z-1 / 2$; hydrogen atoms, methanol and water molecule are omitted for clarity).

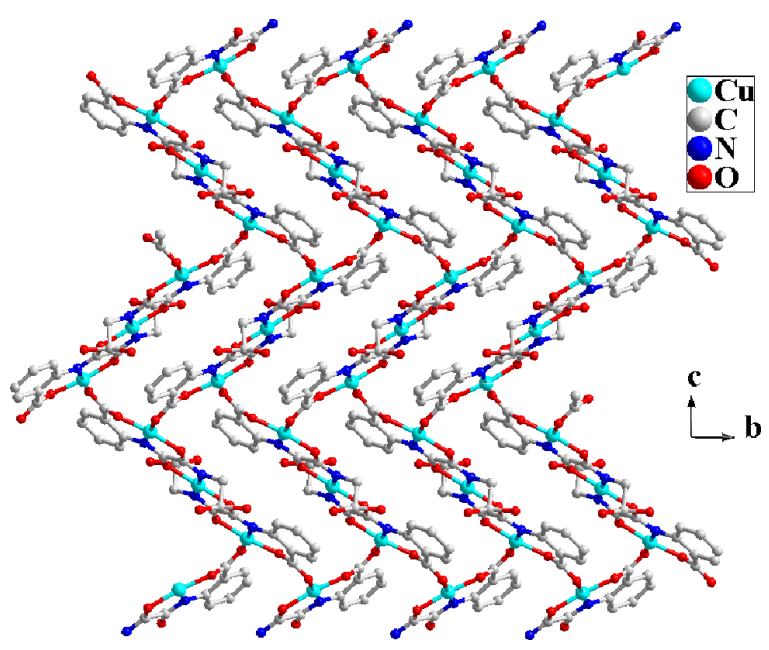

Fig. 2. The 2D structure of complex $\mathbf{1}$ as seen along the crystallographic $a$ axis (hydrogen atoms, methanol and water molecules are omitted for clarity).

gen atom $(\mathrm{O} 2 \# 2)$ from another trans-oxamidate bridge. The axial positions are filled with one oxygen atom (O1W) from water, and one oxygen atom (O6) from methanol. Fig. 1 indicates that $\mathrm{O} 5$ is disordered over two sites.

These trinuclear units are linked by coordinative bonds between carboxylic oxygen atoms and $\mathrm{Cu}$ ions to form a novel double helical 2D coordination polymer, as illustrated in Fig. 2.

As noted earlier, each carboxylate group in the dissymmetrical ligand is in the syn-anti conformation and bridges two copper atoms via its two oxygen atoms. The bridging $\mathrm{Cu}-\mathrm{O}-\mathrm{C}-\mathrm{O}-\mathrm{Cu}$ pathway observed here gives rise to an interesting helical structure. Besides the 


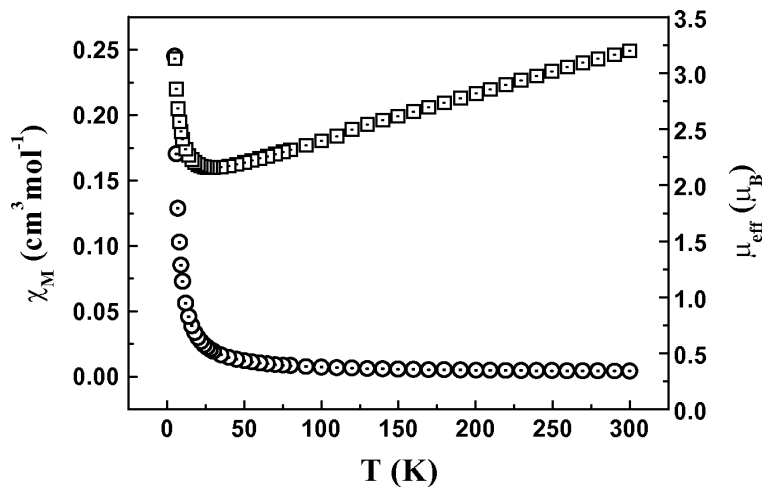

Fig. 3. $\chi_{\mathrm{M}}$ versus $T$ and $\mu_{\mathrm{eff}}$ versus $T$ plots for complex $\mathbf{1}$.

syn-anti mode of the carboxylate, the cis arrangement of the two carboxylate ligands around the metal ion is important for the occurrence of the helical structure. Because left-handed and right-handed helical chains coexist in the crystal structure, the whole crystal does not exhibit chirality. The occurrence of a helical structure in compound $\mathbf{1}$ is attributable to the fact that the steric orientation of the carboxyl groups is remarkably flexible.

\section{Magnetic properties}

The magnetic susceptibility of the complex has been measured in the range of $5-300 \mathrm{~K}$. The curves of
$\chi_{\mathrm{M}}$ and $\mu_{\mathrm{eff}}$ versus Tare shown in Fig. 3. At r.t., the $\mu_{\text {eff }}$ value of complex 1 is $3.20 \mu_{\mathrm{B}}$, which is slightly larger than that expected for uncoupled trinuclear ions $\left(3.00 \mu_{\mathrm{B}}\right)$. Upon cooling, the $\mu_{\mathrm{eff}}$ value of the complex decreases regularly, approaching a minimum around $30 \mathrm{~K}$ with $\mu_{\text {eff }}=2.15 \mu_{\mathrm{B}}$. Finally, the $\mu_{\text {eff value of com- }}$ plex 1 increases as the temperature is further lowered to $5 \mathrm{~K}$, which is possibly due to a ferromagnetic interaction between the trinuclear units through the syn-anti carboxylate bridges.

\section{Conclusion}

In summary, a novel helical 2D coordination polymer has been synthesized and characterized structurally and magnetically. In this complex, trinuclear units are linked by coordination bonds between carboxylic oxygen atoms and $\mathrm{Cu}$ ions to form a novel 2D coordination polymer. To our knowledge, complex $\mathbf{1}$ is the only helical coordination polymer containing both dissymmetrical trans-oxamidate bridges and syn-anti carboxylate bridges. The magnetic properties were discussed with respect to the crystal structure.

\section{Acknowledgement}

We acknowledge the generous financial support of the Natural Science Foundation of Henan Province (No. 092300410031).
[1] a) B. F. Hoskins, R. Robson, J. Am. Chem. Soc. 1990, 112, 1546 - 1554; b) R. Robson, B. F. Abrahams, S. R. Batten, R. W. Gable, B. F. Hoskins, J. Liu, Supramolecular Architecture, American Chemical Society, Washington, DC, 1992, chapter 19; c) O. M. Yaghi, G. Li, Angew. Chem. 1995, 107, 232-234; Angew. Chem., Int. Ed. Engl. 1995, 34, 207 -209; d) J. R. Black, N. R. Champness, W. Levason, G. Reid, Inorg. Chem. 1996, 35, $4432-4438$; e) L. Carlucci, G. Ciani, D. M. Proserpio, A. Sironi, Inorg. Chem. 1995, 34, 5698-5700.

[2] M. Fujita, Y. J. Kwon, S. Washizu, K. Ogura, J. Am. Chem. Soc. 1994, 116, 1151-1552.

[3] a) O.M. Yaghi, C.E. Davis, G. Li, H. Li, J. Am. Chem. Soc. 1997, 119, 2861-2868; b) S. Kawata, S. Kitagawa, H. Kumagai, C. Kudo, H. Kamesaki, T. Ishiyama, R. Suzuki, M. Kondo, M. Katada, Inorg. Chem. 1996, 35, 4449-4461; c) H. Zhang, X. Wang, B. K. Teo, J. Am. Chem. Soc. 1996, 118, $11813-$ 11821.

[4] a) M. S. E. Fallah, E. Rentschler, A. Caneschi, R. Sessoli, D. Gatteschi, Angew. Chem. 1996, 108, $2081-$ 2083; Angew. Chem., Int. Ed. Engl. 1996, 35, $1947-$
1949; b) H. Miyasaka, N. Matsumoto, H. Okawa, N. Re, E. Gallo, C. Floriani, J. Am. Chem. Soc. 1996, 118, $981-994$.

[5] a) J.M. Lehn, Supramolecular Chemistry: Concepts and Perspectives, VCH, Weinheim, 1995; b) O.M. Yaghi in Access in Nanoporous Materials, (Eds.: T. L. Pinnavania, M. F. Thorpe), Plenum, New York 1995, pp. 111.

[6] a) O. Sato, T. Iyoda, A. Fujishima, K. Hashimoto, Science 1996, 271, 49-51; b) H. J. Choi, M. P. Suh, J. Am. Chem. Soc. 1998, 120, $10622-10628$.

[7] a) S. R. Batten, R. Robson, Angew. Chem. 1998, 110, 1558-1595; Angew. Chem. Int. Ed. 1998, 37, $1460-$ 1494; b) P. J. Hagraman, D. Hagraman, J. Zubieta, Angew. Chem. 1999, 111, 2798-2848; Angew. Chem. Int. Ed. 1999, 38, 2638-2684; c) A. J. Blake, N. R. Champness, P. Hubberstey, W. S. Li, M. A. Withersby, M. Schröder, Coord. Chem. Rev. 1999, 183, 117-138.

[8] R. J. Doedens, Prog. Inorg. Chem. 1976, 21, 209-231.

[9] S. J. Rettig, R. C. Thompson, J. Trotter, S. Xia, Inorg. Chem. 1999, 38, 1360-1363.

[10] V. Tangoulis, G. Psomas, C. Dendrinou-Samara, C.P. 
Raptopoulou, A. Terzis, D. P. Kessissoglou, Inorg. Chem. 1996, 35, 7655-7660.

[11] E. Colacio, J. M. Domínguez-Vera, M. Ghazi, R. Kivekäs, M. Klinga, J. M. Moreno, Eur. J. Inorg. Chem. 1999, $441-445$.

[12] E. Colacio, J. M. Dominguez-Vera, R. Kivekäs, J. M. Moreno, A. Romerosa, J. Ruiz, Inorg. Chim. Acta 1993, 212, $115-121$.

[13] K. K. Nanda, A. W. Addison, E. Sinn, L. K. Thompson, Inorg. Chem. 1996, 35, 5966-5967.

[14] D. Schulz, T. Weyhermüller, K. Wieghardt, C. Butzlaff, A. X. Trautwein, Inorg. Chim. Acta 1996, 247, $387-$ 394.

[15] S. Sen, M. K. Saha, T. Gupta, A. K. Karmakar, P. Kundu, S. Mitra, M. B. Hursthouse, K. M. A. Malik, J. Chem. Crystallogr. 1998, 28, 771-777.
[16] a) H. Ojima, K. Nonoyama, Coord. Chem. Rev. 1988, 92, 85; b) R. Ruiz, J. Faus, F. Lloret, M. Julve, Y. Journaux, Coord. Chem. Rev. 1999, 193, $1069-1117$.

[17] a) R. H. Blessing, Acta Crystallogr. 1995, A51, 33 38; b) G. M. Sheldrick, SHELXTL (version 5.1), Bruker Analytical X-ray Systems Inc., Madison, Wisconsin (USA) 1997. See also: G. M. Sheldrick, Acta Crystallogr. 1990, A46, 467-473; ibid. 2008, A64, 112 - 122.

[18] K. Nakamoto, Infrared and Raman Spectra of Inorganic and Coordination Compounds, $5^{\text {th }}$ ed., Part B, John Wiley, New York, 1997.

[19] Y. Akhiff, J. Server-Carrió, J. Garcí-Lozano, E. Escrivá, J. V. Folgado, L. Soto, Inorg. Chem. 1999, 38, $1174-1185$. 